\title{
O CARÁTER EDUCATIVO DAS MOBILIZAÇÕES JUVENIS
}

\author{
Aldimara Catarina Brito Delabona Boutin ${ }^{1}$ \\ Simone de Fátima Flach ${ }^{2}$
}

\begin{abstract}
RESUMO: Este artigo, derivado de pesquisa mais ampla sobre movimentos estudantis, aborda as concepções ideológicas que permearam a atuação de jovens brasileiros em lutas pela ampliação dos seus direitos ou da coletividade social em diferentes contextos históricos. A partir de uma perspectiva histórica baseada em pesquisa bibliográfica, este texto propõe uma reflexão sobre a participação juvenil em diferentes episódios da história brasileira, destacando a atuação de entidades de representação estudantil como a UNE e a UBES, desde 1960 até as atuais reivindicações e protestos dos jovens secundaristas. Tendo como pressuposto teórico o materialismo histórico e dialético, apresentam-se considerações sobre a dimensão educativa dos movimentos estudantis, a qual pode colaborar para o rompimento das amarras ideológicas que imperam na atual sociedade capitalista.
\end{abstract}

Palavras-chave: Movimento Estudantil. Participação. Juventude. Educação.

\section{EDUCATIVE CHARACTER OF YOUTH MOBILIZATION}

ABSTRACT: This paper, derived from broader research on student movements, addresses the ideological concepts that permeated the role of young Brazilians in struggles for the expansion of their rights or the social collectivity in different historical contexts. From a historical perspective based on bibliographical research, this text proposes reflection on youth participation in different episodes of Brazilian history, highlighting the role of student representation bodies such as UNE and UBES, from 1960 to the current vindications and protests of secondaries young students. Given the theoretical assumption of dialectical and historical materialism, considerations on the educational dimension of student movements are presented, which may contribute to the breakdown of ideological ties that prevail in today's capitalist society.

Keywords: Student Movement. Participation. Youth. Education.

\footnotetext{
${ }^{1}$ Mestre em Educação. Doutoranda em Educação pela Universidade Estadual de Ponta Grossa (UEPG). Ponta Grossa-PR/Brasil. E-mail: audiboutin@hotmail.com

2 Doutora em Educação. Docente da Universidade Estadual de Ponta Grossa (UEPG). Ponta Grossa-PR/Brasil. Email: eflach@uol.com.br
} 


\section{EL CARÁCTER EDUCATIVO DE MOBILIZACIONES JUVENILES}

RESUMEN: En este artículo, derivado de investigación más amplia sobre los movimientos estudiantiles, aborda los conceptos ideológicos que impregnaron la actuación de los jóvenes brasileños en luchas por la ampliación de sus derechos o de la comunidad social en diferentes contextos históricos. Desde una perspectiva histórica basada en pesquisa bibliográfica, este artículo propone una reflexión sobre la participación juvenil en diferentes episodios de la historia de Brasil, destacando la actuación de entidades de representación de los estudiantes, tales como la UNE y la UBES, desde 1960 hasta las actuales reivindicaciones y protestas de los jóvenes de la escuela secundaria. Con el supuesto teórico del materialismo histórico y dialéctico, se presentan consideraciones sobre la dimensión educativa de los movimientos estudiantiles, lo que puede contribuir a la ruptura de los lazos ideológicos que prevalecen en la actual sociedad capitalista.

Palabras clave: Movimiento Estudiantil. Participación. Juventud. Educación.

Historicamente, a atuação dos estudantes brasileiros, organizados por meio de entidades como a União Nacional dos Estudantes (UNE) e a União Brasileira dos Estudantes Secundaristas (UBES), entre outras, pode ser compreendida como processo contraditório, pois esteve permeada por diferentes interesses, conforme o momento histórico e os sujeitos envolvidos nesse processo histórico. Contribuem para a reflexão proposta os estudos de Sanfelice (2008) ao exporem a dificuldade em se evidenciar o predomínio de uma ideologia no movimento estudantil liderado pela UNE. No entanto, esse autor enfatiza que isso não significa que essa entidade esteve em algum momento isenta de ideologias, visto que é possível perceber tanto uma oscilação quanto uma mistura de concepções ideológicas.

A análise dos diferentes contextos históricos em que os jovens atuaram igualmente revela uma multiplicidade de ideologias que orientaram a atuação juvenil. Tais ideologias oscilaram entre o desejo pela ampliação dos direitos dos estudantes, por reformas sociais, ou até mesmo pelo rompimento com o modelo político, social e econômico estabelecido no país. É nesse sentido que para a compreensão sobre as múltiplas ideologias que permearam a atuação dos estudantes organizados nas diferentes instituições de representação, se faz necessário tecer considerações sobre as juventudes que atuaram no movimento estudantil brasileiro, já que a juventude não se insere como uma categoria única e particular, pois conforme a concepção de Sanfelice (2013), não existe uma juventude e sim juventudes. 
Dessa forma, o artigo aqui apresentado tem como objetivo discorrer sobre as diferentes juventudes que protagonizaram o movimento estudantil brasileiro e as diferentes concepções ideológicas que permeavam a sua atividade. $\mathrm{O}$ artigo também traz considerações sobre a dimensão educativa dos movimentos estudantis refletindo sobre como estes se estruturam e se organizam no atual contexto histórico.

\section{Revisitando o movimento estudantil brasileiro: reflexões acerca das concepções ideológicas presentes na atuação dos estudantes}

A luta pela ampliação dos direitos estudantis e sociais constitui-se como um marco histórico, uma vez que os jovens, em diferentes contextos, lutaram pela legitimação dos seus direitos, entrando em confronto com as forças dominantes, em diferentes contextos históricos. Uma análise mais atenta do movimento estudantil brasileiro revela a existência de múltiplas juventudes. Contribui para isso Sanfelice (2013) ao discorrer que o movimento estudantil da UNE pautava suas atividades em concepções ideológicas antagônicas, as quais em certos momentos iam ao encontro dos anseios da classe que dominava os setores econômicos ou em outros tinham como objetivo a ampliação dos direitos da classe trabalhadora.

Insere-se como um exemplo sobre a existência de múltiplas juventudes no movimento estudantil brasileiro e sobre as diferentes concepções que permearam a atuação dos jovens, a "Questão dos moços pardos" (CAMARGO, 2005, p. 15), ocorrida na Bahia no ano de 1680, a qual se caracterizou pela proibição dos "jovens pardos e mulatos" em frequentar os estabelecimentos superiores de ensino. Essa proibição teve como justificativa a alegação de que o comportamento desses jovens não era um bom exemplo para os brancos. Ocorre que, discordando da referida proibição, os jovens pardos e negros recorreram ao rei D. Pedro II que, em 1689, "depois de muitos impasses e querelas jurídicas" (SANTOS, 2015, p. 6) permitiu a frequência dos jovens pardos nos colégios metropolitanos (NUNES, 2008).

Poerner (1979) também contribui para a questão, expondo o que considera como o marco inicial da atividade juvenil no Brasil. De acordo com esse autor, no ano de 1710, um grupo de corsários franceses liderados por Francois Duclerc, ao invadirem a cidade do Rio de Janeiro, foram recepcionados negativamente por um número aproximado de quatrocentos 
ou quinhentos jovens que instantaneamente expulsam os intrusos.

Esses estudantes eram oriundos de conventos ou colégios religiosos, já que nessa época ainda não havia universidades no Brasil. Apenas uma pequena parcela da população tinha acesso ao ensino superior, que se referiam aos filhos dos grandes proprietários que enviavam os seus herdeiros a Europa para estudar em universidades (POERNER, 1979).

Em 1786, a atividade estudantil foi marcada pela luta pela Independência do Brasil. O jovem estudante Joaquim Maia, juntamente com onze estudantes brasileiros, escreveu uma carta a Thomas Jeferson solicitando ajuda para a libertação do país do jugo português. Esse acontecimento, de acordo com Mendes Jr. (1982), influenciou a Inconfidência Mineira, pois do grupo de estudantes liderados por Maia, fez parte um jovem que juntamente com Tiradentes protagonizou a Inconfidência Mineira.

A mobilização estudantil que remonta o final do Império Colonial pode ser caracterizada por representar aspirações da classe dominante, pois os estudantes, por meio da atuação política, deixavam evidente o seu descontentamento frente à exploração colonial portuguesa. Nessa perspectiva, a defesa pela abolição da escravidão também se insere como uma luta que irá legitimar os interesses dos grupos dominantes (MENDES JR, 1982).

Tendo como motivação a abolição da escravidão e a luta em prol da República foi fundada as "Sociedades acadêmicas" ou "Clubes acadêmicos" no Rio de Janeiro e em São Paulo. Por meio dessas entidades os jovens se engajaram na campanha pela abolição e não apenas denunciaram o regime escravo, como também se inseriram na luta, auxiliando no planejamento e fuga dos escravos (MENDES JR., 1982).

No entanto, a reflexão sobre tal circunstância histórica nos leva a compreender que a perspectiva de sociedade pelo qual lutavam esses jovens se insere como um interesse não expresso na sua bandeira de reivindicações, uma vez que esses estudantes, sendo oriundos dos grupos dominantes, defendiam projetos de modernização e prosperidade econômica do país. Fausto (2001) expõe que, em 1850, com a aprovação do primeiro Código Comercial, foram definidos "os tipos de Companhias" (p. 108), que poderiam estabelecer relações comerciais no país. Dessa forma, o fim do tráfico negro traria benefícios para a atividade comercial, aumentando as rendas governamentais, contribuindo para o surgimento de bancos e indústrias, melhorando e modernizando o sistema de transportes (FAUSTO, 2001). 
Dessa forma, o sistema escravista significava um entrave para a modernização do país. Diante disso, seria necessário libertar os negros e transformá-los em homens livres, em consumidores e mão de obra comprometida com o desenvolvimento. Nesse contexto, se justifica o envolvimento dos estudantes na luta pela abolição da escravidão, visto que pertenciam, em sua maioria, a famílias que dominavam economicamente.

Em 1914, os estudantes explicitaram para a coletividade social os ideais nacionalistas que permeavam a sua atividade, pois ao se posicionarem favoravelmente aos países aliados no episódio da I Guerra Mundial, criaram e atuaram junto à Liga Nacionalista e à Liga de Defesa Nacional, entidades estas que lutaram pelo fortalecimento do nacionalismo (MENDES JR, 1982; POERNER, 1979). As concepções defendidas pela Liga Nacionalista podem ser caracterizadas como reformistas, uma vez que os estudantes não denunciavam e nem lutavam pela superação dos problemas decorrentes da exploração econômica de uma classe sobre a outra, ao contrário resumiam as mazelas da sociedade ao fraco nacionalismo, como Olavo Bilac enfatizou que um dos grandes defeitos da pátria era "a ausência de formação cívica e a defesa precária do país" (POERNER, 1979, p. 99).

Defendendo que o nacionalismo era um dos caminhos para a verdadeira transformação da sociedade, a Liga Nacionalista almejava com tal discurso atingir as diferentes classes sociais. No entanto, não pleiteava a superação da exploração de uma classe sobre a outra, ao contrário, a ideologia nacionalista, conforme expõe Almeida (2014), integra um recurso para a reprodução e legitimação dos interesses particulares da classe dominante.

A atuação dos estudantes por meio da União Nacional dos Estudantes (UNE), datada de 1937 ou 1938, pode ser considerada como complexa uma vez que sua história é permeada por concepções políticas opostas. As divergências ideológicas apresentadas no movimento estudantil liderado pela UNE são identificadas já na fase inicial da atuação desta entidade, pois no I Conselho Nacional dos Estudantes, realizado em 1937, no Rio de Janeiro, o qual tinha como objetivo criar uma entidade nacional de representação foi proibida a discussão sobre temas políticos, o que só veio a acontecer no II Conselho Nacional dos Estudantes, realizado no ano de 1938 (ARAÚJO, 2007).

O nacionalismo ainda se fez presente no movimento estudantil brasileiro na campanha pela criação da Petrobrás, em 1947 (FÁVERO, 1995). A luta da UNE, nessa campanha, 
expressava as ideologias nacionalistas presentes no movimento estudantil. Esse mesmo nacionalismo caracterizado pelo conservadorismo liberal, que figurou a política populista emergiu, de acordo com Cunha (1982), do interior do Estado e tinha como objetivo buscar estratégias para o desenvolvimento econômico do Brasil.

Os estudantes universitários ainda atuaram em conjunto aos jovens ${ }^{3}$ secundaristas em diferentes situações. A atividade conjunta entre estudantes universitários e a União Brasileira dos Estudantes Secundaristas (UBES) pode ser localizada em episódios como a lua pela meia passagem no transporte coletivo e pela meia entrada em cinemas, shows e espetáculos e também nos diferentes protestos no governo militar de 1964 (ARAÚJO, 2007).

A oscilação entre ideologias socialistas e liberais também se fez presente no movimento estudantil no episódio ocorrido no ano de 1949, em que o estudante direitista Paulo Egydio, então presidente da União Metropolitana dos Estudantes (UME), articulou a candidatura e a vitória para a presidência da UNE de Olavo Jardim Campos. Contudo, de acordo com Poerner (1979), foi um cargo de fachada, pois as decisões tomadas dentro da entidade couberam à estudante norte-americana Helem Rogers, fato este que significou o "início da infiltração norte-americana no movimento estudantil brasileiro" (POERNER, 1979, p. 182). A esquerda retomou a liderança da UNE em 1956, com José Batista de Oliveira Jr., que atuou em aliança com o sindicato dos operários, que originou a UOE (União Operária Estudantil) e chamou a atenção dos Estados Unidos que, tendo como objetivo evitar a propagação de concepções comunistas no movimento estudantil brasileiro, enviou para o Brasil a estudante Glória May, com a missão de romper com a ascensão de filosofias marxistas na UNE (POERNER, 1979).

A oscilação entre concepções ideológicas no movimento estudantil refletiu filosofias conflitantes, pois como foi abordado, a UNE, no período em que esteve sob a liderança dos setores direitistas, abriu espaço para a infiltração americana no movimento, cedendo aos

\footnotetext{
${ }^{3}$ Ainda podemos observar no movimento estudantil a presença de lideranças católicas. A organização de representação estudantil denominada Juventude Universitária Católica (JUC) integrava a organização nacional Ação Católica. Entre o final da década de 1950 e início de 1960, o pensamento dos jovens que atuavam na JUC passou a ser orientado por concepções católicas progressistas e então começaram a debater problemas sociais do Brasil. No Congresso dos Dez anos, realizado no Rio de Janeiro, em 1960, foi aprovado o documento "Diretrizes mínimas para o ideal histórico do povo brasileiro", que apontava para o "socialismo democrático" (SANFELICE, 2008, p. 66). No interior da Ação Católica ainda se desenvolveram outros grupos de atuação estudantil como: Juventude Agrária Católica (JAC), Juventude Estudantil Católica (JEC) e Juventude Operária Católica (JOC) (ARAÚJO, 2007)
} 
estrangeiros não apenas a oportunidade de conduzir as decisões e os rumos da ação estudantil. Isso oportunizou a disciplina dos estudantes segundo a filosofia do capitalismo que imperava nos Estados Unidos.

Os Seminários de Reforma Universitária organizados pela UNE podem ser considerados como eventos que buscaram a conquista e ampliação dos direitos não apenas dos estudantes, mas também da coletividade social. Nesse contexto, o "Primeiro Seminário Nacional de Reforma Universitária", ocorrido em 1960, na cidade de Salvador, originou o documento intitulado de Declaração da Bahia, o qual abordou sobre temas que diziam respeito tanto à realidade social do Brasil como sobre a reforma universitária (FÁVERO, 1995, p. 35).

O Segundo Seminário Nacional da Reforma Universitária, realizado no ano de 1962, em Curitiba, Paraná, originou um documento intitulado de "Carta do Paraná", um modelo de universidade "crítica, antidogmática e imune às discriminações de ordem econômica, ideológica, política e social” (FÁVERO, 1995, p. 40). Já o Terceiro Seminário da Reforma Universitária, de 1963, ocorrido em Belo Horizonte, pretendia ampliar as verbas para o ensino, ampliar a participação dos estudantes em órgãos colegiados nas universidades e reformar o vestibular, entre outros (ARAÚJO, 2007).

A retomada da esquerda na direção da UNE também se caracterizou pelo posicionamento favorável às Reformas de Base do então presidente João Goulart e também pela aliança com entidades estruturadas em concepções nacionalistas como a Frente Parlamentar Nacionalista (FPN), Partido Socialista Brasileiro (PSB) e o Partido Trabalhista Brasileiro (PTB) que "visavam uma luta nacionalista-reformista com o apoio da UNE" (SANFELICE, 2008, p. 35). No entanto, é importante deixar claro que mesmo defendendo os projetos de Reformas de Base, os estudantes podiam ser identificados como um grupo de esquerda e embora seja complexa a tarefa de mapear as tendências ideológicas presentes no movimento estudantil realizado pela UNE, essa entidade "não esteve isenta de ideologias" (SANFELICE, 2008, p. 65) e tais ideologias, por vezes, se revezavam entre concepções que defendiam a superação do modo de produção capitalista ou apenas defendiam a reforma do modelo de sociedade em vigor. 
Na ditadura militar de 1964, a UNE foi uma das primeiras instituições a sofrer com o autoritarismo desse regime. Nesse período houve a lei de autoria do então ministro da educação, Suplicy de Lacerda (lei n. 4.464 de 09 de novembro de 1964), que previa a extinção da União Nacional dos Estudantes, que seria substituída pelo Diretório Nacional dos Estudantes e as Uniões Estaduais pelos Diretórios Estaduais (DEES) (POERNER, 1979, p. 231).

Em 1968, houve a intensificação do ativismo estudantil. Esse ano trouxe como marca a intensidade e frequência da violência praticada pelo governo militar (destaque precisa ser dado à morte do estudante Edson Luís no dia 28 de março de 1968). Esse crime motivou protestos contra o militarismo, os quais tiveram apoio de diferentes setores da sociedade civil (VALLE, 1999).

Outros episódios ainda explicitaram a organização e atuação dos estudantes em protestos contra a ditadura. O episódio conhecido como "o massacre da Praia Vermelha" é marcante na história do movimento estudantil, pois nele houve o emprego da força e da brutalidade policial, mas se particularizou pela adesão de vários setores da coletividade social (VALLE, 1999). Tais acontecimentos, embora trágicos, contribuíram para a construção do sentimento coletivo de que aquela situação não poderia mais ser suportada e deveria ser superada. No dia 26 de junho de 1968, a "Passeata dos cem mil", de acordo com Poerner (1979), difundiu no país uma sensação de que a democracia era possível, sensação esta traduzida em opiniões expressas em artigos de jornais e revistas, livros e festivais de músicas que expressavam o desejo pelo retorno da democracia.

Embora seja unânime o reconhecimento do exagero do emprego da violência no militarismo, é possível identificar algumas divergências entre as concepções ideológicas no interior do Movimento Estudantil. A "Batalha da Rua Maria Antônia”, ocorrida em São Paulo, em 1968, se insere como um bom exemplo dessa argumentação. Nessa batalha houve o confronto entre os alunos de Filosofia da USP (Universidade de São Paulo) e os alunos da Universidade Mackenzie, que possuíam concepções discordantes (SANFELICE, 2008).

Em 1974, iniciou uma nova fase no interior do regime militar, na gestão do general Ernesto Geisel. Nesse ano foram adotadas medidas para a volta "gradual da sociedade brasileira ao regime democrático" (BENEVIDES, 2006, p. 68), e órgãos como a Ordem dos Advogados do Brasil (OAB), Associação Brasileira de Imprensa (ABI) e setores da Igreja 
Católica, passaram a reivindicar o retorno imediato da democracia. A UNE também se envolveu no debate pela democracia, e no ano de 1975 retomou suas atividades e foi reconstruída no Encontro Nacional dos Estudantes (ENE), realizado na USP (ARAÚJO, 2007).

A partir desse contexto histórico, a ditadura iniciou uma fase de enfraquecimento. Em 1983, o deputado federal Dante de Oliveira - PMDB - Mato Grosso, apresentou uma proposta objetivando a realização de eleições diretas para a substituição do presidente Figueiredo e o movimento estudantil foi figura de destaque nas passeatas e manifestações pelo movimento democrático, que ficou conhecido como "Diretas Já" (NETTO, 2014).

A partir dos fatos apresentados, é possível inferir que a história do movimento estudantil brasileiro é permeada por contradições, dificultando a identificação de um perfil ideológico que norteasse as concepções dos jovens nos diversificados contextos históricos em que atuaram. E isso é plenamente justificável, pois tanto Sanfelice (2013) como Costa e Vieira (2006) expõem que no Brasil é possível afirmar a existência de diferentes juventudes. Com base nesse argumento, esses autores discorrem que é difícil traçar um perfil para o jovem brasileiro já que as relações econômicas e sociais influenciam em comportamentos e atitudes.

Para Sanfelice (2013, p. 67), os jovens se diferenciam pelos comportamentos que assumem e por "convenções sociais". Eles incorporam características de acordo com a realidade social e econômica em que se inserem. Assim há jovens que muito cedo se inserem no mercado de trabalho, outros que dedicam seu tempo apenas para os estudos e aqueles que nunca estudaram e outros que frequentam as melhores escolas. Portanto há diferentes movimentos: "da juventude das periferias dos centros urbanos, da juventude das classes médias, da juventude burguesa e da juventude de culturas diferenciadas" (SANFELICE, 2013, p. 69).

Com base nos autores apresentados, a dificuldade em traçar um perfil ideológico para as concepções dos jovens que atuaram em movimentos estudantis pode ser explicada pela diversidade de jovens que atuaram nesses movimentos em diferentes locais e momentos históricos. Conforme exposto, desde o início desta reflexão o movimento estudantil integrou desde jovens estudantes de colégios religiosos e conventos, estudantes de universidades na Europa, alunos das primeiras universidades brasileiras, jovens secundaristas, jovens pertencentes ao movimento estudantil católico, entre outros. 


\section{O movimento estudantil na atualidade: sua dimensão educativa}

$\mathrm{Na}$ atualidade, o movimento estudantil brasileiro se estrutura a partir das entidades de representação dos estudantes universitários e secundaristas, a União Brasileira dos Estudantes (UNE) e a União Brasileira dos Estudantes Secundaristas (UBES). Essas entidades são vinculadas às entidades de representação estudantis estaduais e municipais e também a uma entidade internacional, a Organização Continental Latino Americana e Caribenha dos Estudantes (OCLAE), com sede em Havana (GRÊMIO LIVRE, s/d).

Essa entidade congrega cerca de 150 milhões de membros, que fazem parte das 36 Federações Estudantis do continente americano, distribuídas em 23 países (UNIÃO NACIONAL DOS ESTUDANTES - UNE ${ }^{4}$ a, s/d). Os objetivos principais que norteiam a atuação da referida entidade é a luta pelo acesso igualitário à educação; o fim do analfabetismo; educação pública de qualidade; autonomia universitária; fim do fascismo e do imperialismo e da fome nos países periféricos (UNIÃO BRASILEIRA DOS ESTUDANTES SECUNDARISTAS - UBES5 , s/d).

A UNE, além de atuar junto à OCLAE, também atua em aliança com as “União Estaduais dos Estudantes" (UEE), as quais têm como objetivo o fortalecimento do movimento estudantil regional e nacional, os "Diretório Central dos Estudantes" (DCE), presentes nas diferentes instituições de ensino superior que possuem mais de quatro cursos, e os "Centro Acadêmico" (CA) ou "Diretório Acadêmico" (DA) existentes em cada curso das universidades com o objetivo de realizar reflexões sobre o ensino e a estrutura da universidade brasileira (UNIÃO NACIONAL DOS ESTUDANTES - UNEb $\left.{ }^{6}, \mathrm{~s} / \mathrm{d}\right)$.

A UBES também é entidade filiada à OCLAE e igualmente a UNE também atua em conjunto com as entidades estaduais, no entanto se diferencia por trabalhar juntamente com as entidades municipais de representação dos estudantes e também com os grêmios estudantis. As entidades estaduais representam os estudantes do ensino fundamental, médio e técnico de cada estado e têm como objetivo lutar em torno de questões sociais e políticas. As entidades municipais de representação dos estudantes secundaristas compõem as "União

\footnotetext{
4 União Nacional dos Estudantes (UNE)a. Disponível em: http://www.une.org.br/2014/07/oclae-divulga-a-programacao-doseu-17\%C2\%BA-congresso/. Acesso em: 09 jan. 2016.

5 União Brasileira dos Estudantes Secundaristas (UBES). Disponível em: http://ubes.org.br/2014/congresso-da-oclaeacontece-no-proximo-dia-17-na-nicaragua/. Acesso em: 09 jan. 2016.

6 União Nacional dos Estudantes (UNE)b. Disponível em: http://www.une.org.br/2011/09/estrutura-do-movimentoestudantil/. Acesso em: 09 jan. 2016.
} 
Municipal dos Estudantes Secundaristas" (UME) e em conjunto com estas entidades atuam os Grêmios Estudantis que representam a coletividade dos estudantes do ensino fundamental, médio e técnico das instituições de ensino.

Compreendendo como se estrutura o movimento estudantil na atualidade, se torna possível estabelecer reflexões sobre a sua dimensão educativa no atual contexto. No entanto, antes de propor tal reflexão é necessário tecer algumas reflexões acerca do que se compreende por movimentos sociais.

Para Almeida (2009, p. 142), os movimentos sociais apresentam alternativas para a "ruptura com a ordem hegemonicamente vigente" e se caracterizam por apresentarem possibilidades de mudanças no contexto social, uma vez que se confrontam com as forças dominantes. Gohn (1992) argumenta que a luta dos movimentos sociais por transformações na sociedade é histórica, se destacando a busca por uma educação de qualidade e a plena vivência da cidadania.

Face aos argumentos apresentados, podemos compreender o movimento estudantil como um movimento social, pois as lutas empreendidas pelo movimento dos estudantes se assemelham pela busca por mudanças no contexto social, pela ampliação e conquista de novos direitos em diferentes áreas, sobretudo na educação. Assim como no passado, a luta do movimento estudantil na atualidade busca mudanças no contexto social em que se insere e a educação é uma das principais bandeiras de suas reivindicações juvenis. Basta nos lembrarmos de alguns episódios recentes que figuraram nas manchetes dos principais veículos de comunicação do país.

Em recentes episódios, em 2015, os estudantes secundaristas paulistas protestaram contra o fechamento 94 escolas estaduais propostas pelo governo Alckmin. Esses estudantes, como estratégias de lutas, acamparam nas escolas da rede pública de São Paulo e incorporaram na pauta de reivindicações a ampliação de verbas para a educação, a melhoria

\footnotetext{
7 EL PAÍS - PT. Disponível em: http://www.pt.org.br/alunos-fazem-nova-manifestacao-contra-fechamento-de-escolas-poralckmin/ ou http://brasil.elpais.com/tag/c/b724193e9df6e64e8e8770310e9b8588. Acesso em: 15 jan. 2016.
} 
na infraestrutura da escola, a ampliação na participação da gestão escolar e a valorização dos professores8.

Outros episódios ainda marcam a atividade estudantil na atualidade como, por exemplo, os protestos contra os desvios das verbas para a merenda no governo Alckmin ${ }^{9}$, em São Paulo, ocorridos em 2016, ou a luta dos estudantes paranaenses contra a proposta do governo Beto Richa ${ }^{10}$ - PR em relação ao fechamento de 100 escolas da rede pública de ensino. Houve também as manifestações e atos em solidariedade aos professores paranaenses feridos no ano de 2015, no episódio que ficou conhecido como "Massacre do dia 29 de abril"11.

Esses recentes acontecimentos mostram que o movimento estudantil tem lutado por transformações sociais, buscando sobretudo a legitimação dos direitos da sociedade. É nesse sentido que Almeida (2009) contribui, discorrendo que os movimentos sociais como esses integram

[...] sujeitos históricos coletivos que, na correlação de forças do conjunto da sociedade civil, interferem na dinâmica social na medida em que revelam o conflito dos interesses entre classes antagônicas. Ao fazê-lo, trazem à tona a possibilidade do enfrentamento que pode converter-se na construção da democratização das relações sociais e de produção (ALMEIDA, 2009, p. 144).

Dessa forma, o movimento estudantil contemporâneo agrega as características acima enfatizadas, o que torna possível compreendê-lo como um movimento social e como tal é possível tratar uma dimensão educativa desse movimento, pois conforme expõe Gohn (1992, p. 21) a "educação não se restringe ao aprendizado de conteúdos específicos". Para a autora a educação ocorre "de várias formas", "em vários planos e dimensões que se articulam e não determinam nenhum grau de prioridade".

Assim, compreende-se que os movimentos sociais possuem dimensões educativas e para a autora acima citada tais dimensões requerem:

1) Dimensão da organização política

\footnotetext{
${ }^{8}$ AGÊNCIA BRASIL - EBC. Disponível em: http://agenciabrasil.ebc.com.br/geral/noticia/2015-12/apos-um-mes-de-ocupacaodas-escolas-estudantes-de-sp-continuam-nas-ruas. Acesso em: 20 mar. 2016.

${ }_{9}^{9}$ Disponível em: http://www.blogdefranciscocastro.com.br/2016/03/estudantes-fazem-protesto-contra-roubo.html. Acesso em: 20 mar. 2016.

10 CARTA CAPITAL. Disponível em: http://www.cartacapital.com.br/politica/fechamento-de-escolas-beto-richa-epressionado-e-recua-2644.html. Acesso em: 20 mar. 2016.

11 FOLHA DE SÃO PAULO. Disponível em: http://www1.folha.uol.com.br/poder/2015/04/1623173-estudantes-fazem-atocontra-professores-feridos-em-curitiba.shtml. Acesso em: 20 mar. 2016.
} 
Esta dimensão, para Gohn (1992), se refere ao ato de tomar consciência sobre os direitos e deveres dos sujeitos sociais. Para a autora, a aquisição dessa conscientização não se dá de forma imediata, ela é um processo em construção, e é no seio das contradições da oposição entre os interesses que se constrói tal conscientização.

2) Dimensão da cultura política

É possível aprender por meio das experiências cotidianas e por meio das experiências do passado vivenciadas nos movimentos sociais. Gohn $(1992$, p. 23) discorre que as experiências acumuladas fornecem "elementos para a leitura do presente" e também são importantes para "decodificar o porquê das restrições e proibições". Assim, para essa autora, as experiências possibilitam tanto a elaboração de estratégias de lutas como mostram possibilidades de colocá-las em prática.

3) Dimensão espacial- temporal

Esta dimensão se refere às contribuições para o conhecimento "das condições de vida de parcelas da população, no presente e no passado" (GOHN, 1992, p. 24-25). Dessa forma, os movimentos sociais auxiliam para a "formação de uma visão que historiciza os problemas" (p. 25), o que segundo a autora incorre na "articulação entre o chamado saber popular e o saber científico" (p. 25).

Tomando como base as dimensões educativas abordadas por Gohn (1992), apresentadas nos movimentos populares, é possível compreender que o movimento estudantil possui grande potencial educativo, uma vez que agrega as três dimensões abordadas pela autora citada. E é nesse contexto que o movimento estudantil atua, sinalizando para o conjunto da sociedade os problemas e contradições que nela se inserem, mostrando que a organização e a participação engajada e compromissada com as transformações são componentes que integram o verdadeiro protagonismo juvenil.

\section{Considerações Finais}

A poesia "O analfabeto político"12, de Bertold Brecht explicita o quanto a política está presente nas relações que permeiam a sociedade. Ele discorre que um posicionamento alheio

\footnotetext{
12 O Poema "Analfabeto Político de Bertold Brecht, está disponível em: http://congressoemfoco.uol.com.br/noticias/questaode-foco/o-analfabeto-politico/. Acesso em: 18 jan. 2016
} 
às decisões políticas pode ser definido como analfabetismo político, o que segundo o mesmo é o pior tipo de analfabetismo, uma vez que contribui para o alargamento das contradições apresentadas no contexto da sociedade.

Nesse sentido, considerando que a política é um fator determinante das relações apresentadas no contexto da sociedade, podemos também afirmar que a "educação é um ato político" (SAVIANI, 2015, p. 106), pois de acordo com este autor ela pode contribuir tanto para a manutenção da estrutura social apresentada como para a superação da mesma. Ainda para Saviani (2015, p. 105), a educação se insere como uma "prática social", e sendo assim as contribuições de toda prática educativa residem em possibilitar a compreensão sobre "o modo como se encontra estruturada a sociedade" e os limites nela apresentados. É nesse contexto que destacamos o potencial educativo dos movimentos sociais, uma vez que estes, ao buscarem transformações no âmbito da sociedade, explicitam as contradições e a natureza dos problemas que permeiam uma dada contextualização.

Gohn (1992) também coopera com a argumentação proposta ao esclarecer que os movimentos de massas cooperam para a aquisição da conscientização sobre os limites da sociedade, para a reflexão sobre as possibilidades de ruptura com um modelo político vigente e também possibilitam a historicização dos problemas apresentados no atual contexto social. Os jovens, historicamente, tem se constituído como uma categoria que luta pela ampliação dos direitos, tanto dos estudantes como dos demais setores da sociedade e embora seja complexa a tarefa de delimitar uma característica que predomina nas concepções defendidas pela juventude durante a história do movimento estudantil brasileiro, devemos reconhecer que estes não se inserem como analfabetos políticos, conforme a definição para o termo expressa na poesia de Brechet.

É nesse sentido que podemos compreender que o movimento estudantil brasileiro vem contribuindo para o estabelecimento de uma conscientização no coletivo da sociedade civil de que a participação engajada constitui-se como uma força capaz de romper com as estruturas vigentes, uma vez que as lutas, as reivindicações e a busca pela ampliação dos direitos se inserem como aprendizados, como experiências que educam tanto os jovens como os demais setores da sociedade. Isso torna possível afirmar que o movimento estudantil também possui uma dimensão educativa. 


\section{Referências}

AGÊNCIA BRASIL; EBC. Após um mês de ocupação das escolas, estudantes de SP continuam nas ruas. Março de 2016. Disponível em: <http://agenciabrasil.ebc.com.br/geral/noticia/201512 /apos-um-mes-de-ocupacao-das-escolas-estudantes-de-sp-continuam-nas-ruas $>$. Acesso em: 20 mar. 2016.

ALMEIDA, L. F. R. Ideologia nacional e nacionalismo. São Paulo: Educ, 2014.

ALMEIDA, D. M. M. Entre ações coletivas e subjetividade: o caráter educativo dos movimentos sociais. Eccos Revista Científica, v. 11, n. 1, p. 141 - 156, jan./jun, 2009.

ARAÚJO, M. P. Memórias estudantis: da fundação da UNE aos nossos dias. Rio de Janeiro: Relume Damara, 2007.

BENEVIDES, S. C. O. Na contramão do poder: juventude e movimento estudantil. São Paulo: Anna Blume, 2006.

BLOG FRANCISCO CASTRO. Estudantes fazem protesto contra roubo de merenda no governo do PSBD em SP. Disponível em: <http://www.blogdefranciscocastro.com.br/2016/03/estudantesfazem-protesto-contra-roubo.html>. Data de acesso: 20 mar. 2016.

BRECHT, B. $O$ analfabeto Político. Disponível em: <http://congressoemfoco.uol.com.br/noticias/questao-de-foco/o-analfabeto-politico/. Acesso em: 12 jan. 2016.

CAMARGO, E. P. R. O negro na educação superior: perspectivas das ações afirmativas. Tese (Doutorado em Educação) - Universidade Estadual de Campinas, Campinas-SP, 2005.

CARTA CAPITAL. Fechamento de escolas: Beto Richa é pressionado e recua. Disponível em: <http://www.cartacapital.com.br/politica/fechamento-de-escolas-beto-richa-e-pressionado-erecua-2644.html>. Acesso em: 20 mar. 2016.

COSTA, A. C. G.; VIEIRA, M. A. Protagonismo juvenil: adolescência, educação e participação democrática. São Paulo: FTD, 2006.

CUNHA, L. A. A universidade crítica. Rio de Janeiro: Francisco Alves, 1982.

FAUSTO, B. História concisa do Brasil. São Paulo: Edusp, 2001.

EL PAÍS. Manifestações Estudantis São Paulo. Janeiro, 2016. Disponível em: <http://brasil.elpais.com/tag/c/b724193e9df6e64e8e8770310e9b8588>. Acesso em: 12 jan. 2016.

FÁVERO, M. L. A UNE em tempos de autoritarismo. Rio de Janeiro: UFRJ, 1995.

FOLHA DE SÃO PAULO. Estudantes fazem ato em apoio a professores feridos em Curitiba. Abril, 2015. Disponível em: <http://www1.folha.uol.com.br/poder/2015/04/1623173-estudantesfazem-ato-contra-professores-feridos-em-curitiba.shtml>. Acesso em: 20 mar. 2016.

GOHN, M. G. Movimentos sociais e educação. 8. ed. Porto Alegre: Cortez, 1992.

GRÊMIO LIVRE. Senado Federal: Brasília. Disponível em: <http://www2.senado.leg.br/bdsf/bitstream/handle/id/385450/Gremio\%20Livre.pdf?sequence= 1>. Acesso em: 24 jan. 2016. 
MENDES JR., A. Movimento estudantil no Brasil. São Paulo: Brasiliense, 1982.

NETTO, J. P. Pequena história da ditadura brasileira: 1964 - 1985. São Paulo: Cortez, 2014.

NUNES, A. A. Educação jesuítica na Bahia colonial: Colégio Urbano internato em Seminário noviciado. In: SEGUNDO ENCONTRO INTERNACIONAL DE HISTÓRIA COLONIAL. Anais

eletrônicos [...]. Rio Grande do Norte-RN: 2008, p. 01-14. Disponível em:

<http://www.cerescaico.ufrn.br/mneme/anais/st trab pdf/pdf st1/antonietta nunes st1.pdf $>$. Acesso em: 06 mar. 2016.

POERNER, A. J. O poder jovem: história da participação política dos estudantes brasileiros. Rio de Janeiro: Civilização Brasileira, 1979.

SANFELICE, J. L. Movimento estudantil: a UNE na resistência ao golpe de 64. São Paulo: Alínea, 2008.

SANFELICE, J. L. Breves reflexões sobre juventude educação e globalização. In: MACHADO, L. O (org.). Juventudes, democracia, direitos humanos e cidadania. Minas Gerais: Prospectiva, 2013, p. 66-88.

SANTOS, S. P. Os intrusos e os outros oxigenando a universidade: por uma reação articulada entre raça e classe nas ações afirmativas. In: REUNIÃO NACIONAL DA ANPED, 2015, Florianópolis. Anais eletrônicos [...]. Santa Catarina, 04 a 08 de out, 2015. p. 02-19. Disponível em: $\langle$ http://37reuniao.anped.org.br/wp-content/uploads/2015/02/Trabalho-GT21-4634.pdf >. Acesso em: 5 mar. 2016.

SAVIANI, D. História do tempo e tempo da história. Campinas: Autores Associados, 2015.

UNIÃO BRASILEIRA DOS ESTUDANTES SECUNDARISTAS (UBES). Congresso em Ponta Grossa marca reconstrução da UMESP e reafirma a luta dos estudantes. Disponível em:

<http://ubes.org.br/2012/congresso-em-ponta-grossa-marca-reconstrucao-da-umesp-ereafirma-luta-dos-estudantes>. Acesso em: 09 jan. 2016.

UNIÃO BRASILEIRA DOS ESTUDANTES SECUNDARISTAS (UBES). Congresso da OCLAE acontece no próximo dia 17 na Nicarágua. Disponível em: <http://ubes.org.br/2014/congresso-da-oclaeacontece-no-proximo-dia-17-na-nicaragua/. Acesso em: 09 jan. 2016.

UNIÃO NACIONAL DOS ESTUDANTES (UNE)a. OCLAE divulga a programação do seu 17 congresso. Disponível em: <http://www.une.org.br/2014/07/oclae-divulga-a-programacao-doseu-17\%C2\%BA-congresso/>. Acesso em: 09 jan. 2016.

UNIÃO NACIONAL DOS ESTUDANTES (UNE)b. Estrutura do movimento estudantil. Disponível em: <http://www.une.org.br/2011/09/estrutura-do-movimento-estudantil/>. Acesso em: 09 jan. 2016.

VALLE, M. R. 1968, o diálogo é a violência: movimento estudantil e ditadura militar no Brasil. Campinas: Editora da Unicamp, 1999. 